\title{
Indoxacarb poisoning: An unusual presentation as methemoglobinemia
}

\author{
Lakshmi Prasanna, S. Manimala Rao, Vishal Singh, Rash Kujur, Gowrishankar
}

We describe the management of a case of methemoglobinemia secondary to ingestion of indoxacarb, an oxadiazine insecticide.

Key words: Indoxacarb; methemoglobinemia

\section{Introduction}

Indoxacarb is an oxadiazine insecticide, which acts by blocking sodium channels in the nervous system of insects and causes mild tremors, cessation of feeding, and death in a couple of hours. Contact with the substance can take place through ingestion, physical contact, translaminar action, during preening, and at rewetting of surfaces. ${ }^{[1]}$

In our patient methemoglobinemia occurred following ingestion of indoxacarb in a suicidal attempt. This case report highlights the importance of considering the possibility of methemoglobinemia in cases of exposure to indoxacarb and its early recognition and management.

\section{Case Report}

A 48-year-old male farmer came to the emergency department in the early hours of the day, with a history of consumption of unknown poison (suicidal attempt) followed by vomiting. He had received gastric lavage and atropine at a local hospital. On examination, his Glasgow coma scale score was 13/15 and afebrile. His vital signs

From:

Department of Anaesthesiology and Critical Care, Yashoda Hospitals, Somajiguda, Hyderabad, India

\section{Correspondence:}

Prof. S. Manimala Rao, 6-3-347/17A, Dwarakapuri Colony, Panjagutta, Hyderabad-500 082, AP, India. E-mail: manimalarao@hotmail.com were stable. He was shifted to Acute Medical Care Unit (AMCU) with oxygen supplementation.

On examination in AMCU, the patient was drowsy and hypoventilating, his pupils were bilaterally mid-dilated and reacting to light, His $\mathrm{SpO}_{2}$ was $86 \%$ on 6 lit / min of oxygen at Therefore, a decision was taken to intubate the patient and commence mechanical ventilation and commence mechanical ventilation. Organophosphorus poisoning was suspected and Atropine $0.2 \mathrm{mg} / \mathrm{hr}$ and PAM-200 mg/hr infusions were started. Routine and special investigations were carried out and the results were : S.Cholinesterase- $0.76 \mathrm{KU} / \mathrm{L}$ (0.6-1.5), blood for barbiturates was negative, stomach wash for barbiturate and benzodiazepines negative, LFT showed SGOT of $128 \mathrm{IU} / \mathrm{L}$, SGPT of $109 \mathrm{IU} / \mathrm{L} ; \mathrm{S}$. Creatinine was normal, Urine-pH-5.8, Specific gravity-1.016, no pus cells, no RBC, TLC-18,600.

On the same day in the evening, the patient's blood was noticed to be muddy brown in colour, and peripheral cyanosis (bluish brown) was noticed. An arterial blood gas analysis revealed a $\mathrm{paO}_{2}$ of $347 \mathrm{mmHgon}$ a $\mathrm{FiO}_{2}$ of 0.6 and the $\mathrm{SpO}_{2}$ was only $86 \%$. The patient's relatives were thoroughly questioned again regarding the poison and they brought the tin from which the patient consumed the poison. It was examined and found to be INDOXACARB, a non-organophoshorous oxadiazine insecticide. PAM

\section{Free full text available from www.ijccm.org}


and atropine were stopped. After ruling out other poisons, and with a high degree of suspicion, Methemoglobinemia was considered which could be secondary to ingestion of indoxacarb. Blood was sent for methemoglobin level and co-oximetry. Methemoglobin level was found to be $33.4 \%$. Immediately sterile inj. Methylene blue in $100 \mathrm{ml}$ normal saline, was administered intravenously at a rate

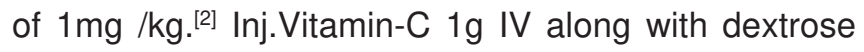
containing fluids. Methylene blue $60 \mathrm{mg}$ IV BD and Inj. Vitamin-C $1 \mathrm{~g}$ IV were continued. The patient gradually started showing signs of improvement and his $\mathrm{SpO}_{2}$ gradually improved to $92-95 \%$ on day two. The patient was gradually weaned off ventilatory support. The $\mathrm{SpO}_{2}$ increased to $95 \%$ on day three and to $95-97 \%$ on day four. The patient was subsequently extubated on day four and continued to maintain a good gas exchange on face mask oxygen. On day five, the $\mathrm{SpO}_{2}$ was $98 \%$ on face mask with 5 liters/min. of oxygen. On day six, the methemoglobin level was $2 \%$. The patient was discharged from ICU on day seven.

Thus our patient was managed successfully with methylene blue and other supportive/symptomatic treatment for methemoglobinemia which was probably secondary to indoxacarb poisoning.

\section{Discussion}

Indoxacarb is an oxadiazine pesticide used for control of cotton bollworm and native budworm in cotton and soyabeans. ${ }^{[3]}$ Our patient had consumed indoxacarb in a suicidal attempt. In the above mentioned case, our patient had developed peripheral cyanosis and had muddy brown discoloration of blood. With an index of suspicion, after ruling out other poisonings, methemoglobinemia was diagnosed and treated. Methemoglobin is generated by oxidation of the heme iron moieties to ferric state, causes bluish-brown muddy color resembling cyanosis. It has got very high affinity to oxygen and oxygen is not delivered to the tissues (oxygen dissociation curve shifted to the left). It is suspected in patients with hypoxic symptoms who appear cyanotic but have a sufficiently high $\mathrm{PaO}_{2}$. Muddy appearance of freshly drawn blood is a critical clue for diagnosis. ${ }^{[2]}$ Normal Meth-Hb levels are $<1 \%$. The physiologic reduction of MethHb Fe3+ to $\mathrm{Hb} \mathrm{Fe}_{2}+$ is mainly accomplished by red cell NADH-cytochrome b5 reductase.

It is manifested by Muddy or Chocolate brown colored fresh blood, Bluish discoloration of skin and mucosa (at $1.5 \mathrm{~g} \%$ or $10 \%$ of meth-hb), irritability, seizures. Cerebral ischemia occurs at $>15 \%$ and $>60 \%$ are lethal. ${ }^{\left[{ }^{[2]}\right.}$

It can be congenital or acquired due to drugs/chemicals. It can be diagnosed by co-oximetry, ${ }^{[4]}$ methemoglobin levels, ${ }^{[4]} \mathrm{ABG}, \mathrm{SpO}_{2}$. In our patient methemoglobin was $33.4 \%$ and the patient had all the classical clinical features.

Treatment includes ceasing the offending agent, correcting the metabolic abnormalities, administering methylene blue at a dose of $1-2 \mathrm{mg} / \mathrm{kg}$ loading dose q 30-60 $\mathrm{min}$, to a maximum of $7 \mathrm{mg} / \mathrm{kg}$, followed by 50-100 mg twice or thrice daily ${ }^{[4]}$ and other supportive measures as required. In our patient, we instituted treatment with $1 \mathrm{mg} / \mathrm{kg}$ of methylene blue as a loading dose, followed by $60 \mathrm{mg}$ twice daily. Methylene blue gets reduced to leucomethylene blue which in turn reduces methemoglobin by NADPH reductase. Methylene blue reduces half-life of methemoglobin from 15-20 hours to 40-90 minutes. We also administered vitamin $C 1 \mathrm{gm} /$ day and dextrose containing fluids for supplementing NADH/ NADPH which is needed for reduction of methemoglobin by NADPH reductase enzyme. The patient's ventilation was supported mechanically for few days. He made an uneventful recovery and was discharged home after seven days.

In our patient, methemoglobinemia had occurred following ingestion of indoxacarb, a pesticide, which was identified due to a high degree of suspicion and treated early with methylene blue. Literature search for methemoglobinemia secondary to indoxacarb did not retrieve any articles. Toxic effects of indoxacarb in humans are not described. ${ }^{[5]}$ Hence, this case report of methemoglobinemia secondary to indoxacarb poisoning.

\section{References}

1. New Pest Management Tools: Integrating Biotech, New Chemistry, and Regulations. A Report on the ESA Section F Symposium held during the ESA National Meeting in Ft. Lauderdale, FL. [cited on 2002 Nov 18],. Available from http://www.entsoc.org/Protected/ AMT/AMT28/Text/Other/ConferenceReport.html.

2. Benz EJ. Hemoglobinopathies. In: Kasper DL, Braunwald E, Fauci AS, Hauser SL, Longo DL, Jameson JL, editors. Harrisons principles of internal medicine. 16th ed. Vol. 91. New York: 
McGraw-Hill; 2005. p. 597-8.

3. Public release summary on Evaluation of the new active Indoxacarb (S-Isomer) in the product DUPONT STEWARD EC INSECTICIDE. Australian Pesticides and Veterinary Medicine Authority. [cited on 2007 Feb]. Canberra. Australia. Available from: http://www.apvma.gov.au/publications/downloads/prs_indoxa(s). pdf.

4. Verive M, Kumar M. Methemoglobinemia. In eMedicine Specialties
> Pediatrics: Hematology > Hematology.

5. Indoxacarb - toxicity, ecologicial toxicity and regulatory information. Available from: http://www.pesticideinfo.org/Detail_Chemical. jsp?Rec_ld=PC36207.

Source of Support: Nil, Conflict of Interest: None declared. 